\title{
The Role of the Clinical Educator in Teacher Preparation: An Exploratory Study of Perceptions of Preparedness
}

Excelsior: Leadership in Teaching and Learning 2018, Vol. 11(1) 4-17

(C) The Author 2018 CC-BY 4.0 International Reprints and permissions: surface.syr.edu/excelsior https://doi.org/10.14305/jn.1 9440413.2018.11.1.01

\section{Kristen M. Driskill ${ }^{1}$}

\begin{abstract}
As the demands on P-12 teachers increase, so do the demands on teacher preparation programs. In higher education institutions across the country, coursework is regularly updated to reflect changing academic standards, increasing diversity in classrooms, rigorous certification exams, etc. In addition, accreditation standards have been updated to reflect the need for P-12 partnerships in best preparing teacher candidates. As a result, clinical practice has come under focus. Yet the role of the clinical educator remains unclear. There is a gap in the literature regarding the preparedness and support of clinical educators, particularly addressing their role in developing teacher candidates along with higher education faculty. The assumption is that P-12 partners are prepared to co-construct experiences for teacher candidates. But, in specifically looking at clinical educators' preparedness, there is a small research base. In response, this paper presents a quantitative study of clinical educators' perceptions of their role in mentoring teacher candidates.
\end{abstract}

\section{Keywords}

teacher education, clinical practice, clinical educator, professional development, teacher perceptions

As the demands on P-12 teachers increase, so do the demands on teacher preparation programs. In higher education institutions across the country, coursework is regularly being updated to reflect changing academic standards, changing populations of students, increasing amounts of diversity in classrooms, more rigorous certification exams, among others. In addition, accreditation standards have been updated to reflect the need for P-12 partnerships in best preparing teacher candidates for future employment. Teacher preparation programs and P-12 institutions are collaborating in new and innovative ways in order to reflect on current practices and seek ways to update programs to best reflect the field. As a result, clinical practice has become a significant area of focus.

\footnotetext{
${ }^{1}$ Roberts Wesleyan College, 2301 Westside Drive, Rochester, NY, 14624

Email: Driskill_Kristen@roberts.edu
} 
Ample research exists regarding the need for clinical experience. While it is now an expired accreditation system, the National Council for the Accreditation of Teacher Education's Blue Ribbon Panel Report on Clinical Preparation and Partnerships described the need for teacher preparation programs to shift in order to provide experiences that are "fully grounded in clinical practice and interwoven with academic content and professional courses" (National Council for the Accreditation of Teacher Education [NCATE], 2010, pg. 11). Those clinical experiences should not occur in isolation, but should be what grounds the learning that occurs throughout a teacher preparation program (Boyd et al., 2009). It is through quality clinical experiences that teacher candidates are able to learn and practice; applying what is learned in the college classroom to the P-12 classroom, analyzing the impact on P-12 students, and reflecting on the experience is what best prepares teacher candidates (Darling-Hammond \& Baratz-Snowden, 2007; Zeichner, 2010). In addition, mentoring and coaching occurs during clinical experiences directly in the context of the P-12 classroom. This provides teacher candidates with support as they make instructional decisions with P-12 students, which deepens the learning experience (DarlingHammond \& Baratz-Snowden, 2007).

This early research paved the way for revised, rigorous standards from the Council for the Accreditation of Educator Preparation, or CAEP. CAEP's next generation of accreditation standards truly raises the bar for teacher preparation programs in many ways, but the need to shift the focus of clinical practice is clearly represented in the new set of standards (CAEP Commission on Standards and Performance Reporting, 2013). Standard 2, which is solely focused on clinical partnerships and practice, requires teacher preparation programs to build partnerships and support clinical educators in order to provide rich clinical experiences for teacher candidates (Council for the Accreditation of Educator Preparation [CAEP], 2015). Not only do clinical experiences need to be strong, but they also must be co-constructed, supervised, and assessed along with P-12 partners (CAEP, 2015).

In the research, attention has been paid in varying degrees not only to the need for effective clinical experiences, but also to the need for P-12 partnerships, the impact of clinical experiences on student learning, and pedagogies of teacher education. There is also a strong research base that supports the importance of the role of the P-12 mentor teacher, or clinical educator, in preparing teacher candidates (Grossman, 2010). However, there is a gap in the literature regarding the preparedness and support of clinical educators, particularly addressing their role in developing teacher candidates in collaboration with higher education faculty. The common assumption is that P-12 partners are well prepared to coconstruct experiences for teacher candidates that will prepare them to be effective educators. But, in specifically looking at clinical educators' preparedness, there is a very small research base. In response, this paper presents an exploratory quantitative study aimed at ascertaining clinical educators' perceptions of their role in mentoring teacher candidates.

\section{Literature Review}

Before engaging in any research, a clear definition of the term "clinical" is necessary. The term "clinical educator" is used in the CAEP accreditation standards (CAEP, 2015), but inconsistently across the literature. Comparisons can be made between education and the medical field, where clinical educators are a foundational part of education programs. In addition, examining the call for clinical educators as is required in accreditation standards is helpful to frame this research. The literature review, while limited in scope, provided background information to launch the study. 


\section{Unpacking "Clinical"}

The phrase "clinical educator" is one that is widely used, yet may not have a consistent definition. Some universities employ "clinical faculty," who are experienced teachers well-versed in mentoring prospective teachers (NCATE, 2010). Others rely on "clinical supervisors," who act as a link between the P-12 school and the teacher preparation program (Grossman, 2010). Still others use "clinical educators" to prepare teacher candidates for the workforce (CAEP, 2015; Higgs \& McAllister, 2007). The titles of university liaison, site facilitator, cooperating teacher, mentor teacher, collaborating teacher, or school liaison are also found across the literature (American Association of Colleges for Teacher Education [AACTE], 2018). Across educational research, these titles are used interchangeably, and the role is only vaguely defined. A common lexicon is clearly needed in regard to clinical preparation of teacher candidates (AACTE, 2018). In comparison, the role of the clinical educator is more clearly defined in the medical field.

A "clinical educator" in the medical field is an expert who uses their knowledge and experience to mentor novices in a clinical setting (Kumar \& Greenhill, 2016). Time is spent in the workplace with the novice to supervise, provide feedback, and help the novice transition into practice (Kumar \& Greenhill, 2016). The clinical educator has a dual role, both as an educator and as a practitioner; they consult and coordinate with university or college programs, as well as support the development of the novice (Morrison, 2016). The clinical educator usually, but perhaps not always, engages in training and ongoing support regarding what clinical teaching involves (Morrison, 2016).

The focus on the "clinical educator" within the field of education has surfaced with the establishment of new accreditation standards from the Council for the Accreditation of Educator Preparation, or CAEP (2016). According to the CAEP standards, clinical educators are "all education preparation providers (EPP) and P-12-school-based individuals, including classroom teachers, who assess, support, and develop a candidate's knowledge, skills, or professional dispositions at some stage in the clinical experiences" (CAEP, 2016, p. 177). In this new context, clinical educators are those from both higher education and P-12 settings; they are higher education faculty that provide campus-based classroom instruction, as well as P-12 classroom teachers who mentor teacher candidates through clinical experiences, both of whom support the teacher candidate to apply theory to practice.

\section{Clinical Practice}

According to AACTE (2018), "clinical practice intentionally connects course work and field work so that teacher candidates can experience, with support, the interplay between the two" (p. 35). Since teaching is a "practice profession," clinical experiences must be structured to allow teacher candidates to apply theory to practice (CAEP, 2015). It is through clinical practice that teacher candidates are able to learn, practice, and demonstrate mastery of pedagogical practices (CAEP, 2015). While the inclusion of clinical practice in teacher preparation programs is not new, there is now a greater focus on the depth of clinical practice.

There is a significant shift in perspective; it is no longer the sole job of the teacher preparation program to prepare teacher candidates for future teaching. Teacher preparation programs can no longer develop and revise programs, create curriculum, plan clinical experiences, establish expectations for performance in clinical experiences, develop key assessments, and monitor student progress without any other stakeholder input (AACTE, 2018). Rather, it is the job of both teacher preparation programs and P-12 
partners to work together to develop shared expectations and experiences for teacher candidates (AACTE, 2018; CAEP, 2015). No longer do P-12 teachers serve only a supporting role in developing teacher candidates, typically more often at the end of a program during student teaching. Within this new context, P-12 teachers are equally involved in the preparation of teacher candidates, during clinical experiences that happen throughout a teacher preparation program, as well as in the updating of coursework to address current trends in the field (AACTE, 2018). There are suggestions in the literature that address this type of systemic change around clinical preparation. However, the role of the clinical educator in preparing teacher candidates for the field remains unclear within existing systems for clinical preparation (CAEP, 2015).

\section{Need for Partnerships}

According to CAEP (2015), "educator preparation providers (EPPs) seeking accreditation should have strong collaborative partnerships with school districts and individual school partners, as well as other community stakeholders, in order to pursue mutually beneficial and agreed upon goals for the preparation of education professionals." With the shift in perspective around the shared responsibility for teacher preparation, teacher preparation programs are now being held accountable for the partnerships established with P-12 districts. CAEP standard 2 is solely dedicated to clinical partnerships and practice: "the provider ensures that effective partnerships and high-quality clinical practice are central to preparation so that candidates develop the knowledge, skills, and professional dispositions necessary to demonstrate positive impact on all P-12 students' learning and development" (CAEP, 2015). These partnerships are mutually beneficial; $\mathrm{P}-12$ partners can help inform teacher preparation practices in order to reflect current trends in the field, and teacher preparation programs can provide P-12 partners with highly qualified teachers. There is a reciprocal benefit to supporting teacher candidate development (AACTE, 2018).

The responsibility of preparing teacher candidates does not lie with the teacher preparation program alone, but with the P-12 partners as well. Component 2.2 of CAEP standard 2 is focused on the "clinical educator." The component requires that:

Partners co-select, prepare, evaluate, support, and retain high-quality clinical educators, both EPP and school-based, who demonstrate a positive impact on candidates' development and P12 student learning and development. In collaboration with their partners, providers use multiple indicators and appropriate technology-based applications to establish, maintain, and refine criteria for selection, professional development, performance evaluation, continuous improvement, and retention of clinical educators in all clinical placement settings (CAEP, 2018).

Stakeholders must be intentional when identifying selection criteria and choosing clinical educators. This is something that typically is done at the P-12 district level, not necessarily with input from teacher preparation programs, and varies from school district to school district (McIntyre, 2017). In addition, partnerships must provide ongoing professional development and support to clinical educators in order to retain them, which is not necessarily something that is widely done (McIntyre, 2017). In order to attract, train, support, and retain highly qualified clinical educators who will mentor teacher candidates, partnerships between teacher preparation programs and P-12 districts are essential.

Not only is there a need to establish partnerships to satisfy accreditation requirements, but also to enhance the clinical experiences in which teacher candidates participate (AACTE, 2018). Effective clinical experiences involve clear goals among all involved, modeling of best practice by experts, frequent 
opportunities for practice in order to provide targeted feedback or coaching, multiple opportunities to bridge theory with practice, a gradual release of responsibility, and ample opportunities for reflection (Darling-Hammond \& Baratz-Snowden, 2007). In order to accomplish all of these, teacher preparation programs must work with P-12 partners to come to consensus. Goals for program outcomes should be established collaboratively so higher education faculty, clinical educators, and teacher candidates are all in agreement (CAEP, 2015; NCATE, 2010). What constitutes best practice should be discussed and agreed upon so teacher candidates are hearing the same messages both on and off campus. Partners should discuss ways in which students can connect theory with practice in a P-12 classroom, and the gradual release of responsibility should be used across both university and college classrooms and P-12 classrooms. It is only through strong partnerships can these expectations be set in order to provide a quality clinical experience for teacher candidates.

Ultimately, both teacher preparation programs and P-12 districts share a "common goal of preparing effective teachers for improved student achievement" (NCATE, 2010, p. 3). Together, both higher education and P-12 faculty must provide rich experiences for teacher candidates to not only put theory into practice, but focus on P-12 student achievement as they do. Given this shared responsibility and focus on strong partnerships, there is an even greater need for quality clinical educators. However, the specifics about their role remains unclear.

\section{Types of Clinical Models}

In the healthcare field, clinical education is the foundation of education programs (Higgs \& McAlliser, 2007). Learning occurs within communities of practice, in which learning is "process-oriented, activitybased, performance-related, problem-based" (Higgs \& McAllister, 2007, p. 52). These programs integrate course work, laboratory experiences, and clinical practice to train future healthcare providers (NCATE, 2010). Students may begin by analyzing actual case studies in order to diagnose a patient's conditions, working both with the academic faculty and clinical faculty to bridge course work with real life situations (NCATE, 2010). Students then move onto laboratory experiences, in which they may engage in such tasks as "learn[ing] to take histories and do a physical exam...with a trained actor, who can simulate certain kind of problems for novices" (Grossman, Hammerness, \& McDonald, 2009, p. 285). Medical students then move onto residencies, during which time novice physicians are supervised by experienced physicians (Grossman, Hammerness, \& McDonald, 2009). Coaching plays a large role within this model of clinical education. Novices engage in opportunities to try out or apply new learning in real contexts, and experts provide immediate feedback about what worked, what didn't work, and why (Grossman, Hammerness, \& McDonald, 2009). This model relies on both research and clinical faculty, allowing novices to use their knowledge to inform their practice (NCATE, 2010).

Like medicine, teaching is a "profession of practice," in which teachers use their knowledge to promote student learning and engage in ongoing practice to continuously develop their professional knowledge (NCATE, 2010). Therefore, providing multiple opportunities to "practice" teaching in various contexts can best prepare teacher candidates to work in actual classrooms (Grossman, Hammerness, \& McDonald, 2009). There is a range of contexts, from the university or college classroom to laboratory-type classrooms to actual P-12 classrooms (Grossman, Hammerness, \& McDonald, 2009). Typically, when teacher candidates learn to use a particular instructional strategy, they may practice it in their university or college classroom; they may plan a hypothetical lesson using the strategy, and then implement the lesson with their peers (Grossman, Hammerness, \& McDonald, 2009). This provides an 
initial opportunity to receive immediate feedback, both from the faculty and from peers (Grossman, Hammerness, \& McDonald, 2009). However, that feedback is likely to focus on surface-level elements. In order to deepen teacher candidates' understanding, opportunities to implement the lesson in a laboratory-type classroom are warranted. In this type of controlled environment, the teacher candidate gets more practice in a more authentic setting (Grossman, Hammerness, \& McDonald, 2009). Immediate, targeted feedback can again be given, but in this context the feedback can focus on impact on P-12 students. This feedback informs the teacher candidates' reflection on his or her practice in a different way, focusing more on student achievement than on theoretical learning.

Scaffolding opportunities for teacher candidates to practice teaching in this type of model mirrors the type of training in which medical students engage (Grossman, Hammerness, \& McDonald, 2009). Similar to a teaching hospital, this model for clinical practice in the education setting would allow clinical educators, "mentors, coaches, teacher interns and residents to work together to better educate students and prospective teachers as part of clinical practice teams" (NCATE, 2010). Through ongoing practice and feedback from clinical educators obtained in authentic settings, teacher candidates can more easily bridge theory with practice, analyze and address problems of practice, and engage in inquiry and reflection about teaching and learning (AACTE, 2018; Darling-Hammond \& Baratz-Snowden, 2007). This model for clinical practice aligns well with the new context set forth by updated CAEP accreditation standards for teacher preparation programs. As teacher preparation programs reflect on current practices and work to improve clinical experiences, this model for clinical practice may become more widely used. If so, the role of the clinical educator will become even more important than before, as will the need for a clear definition of the role, ample preparation to coach and mentor teacher candidates, and ongoing support throughout the clinical experience. When these steps are taken to clarify the role of the clinical educator and provide preparation and support in working with teacher candidates, the gap in the literature around clinical educators will begin to dissipate.

\section{Methodology}

In considering the limited research focused on clinical educators' role and specific responsibilities in mentoring teacher candidates, the goal of this study was to ascertain how current clinical educators perceive their role, including their perceived level of preparedness, perceived level of support, and overall perceptions regarding their responsibility in developing teacher candidates. The specific research questions examined in the study are:

Research Question 1: What are clinical educators' perceptions of the scope of their role to prepare teacher candidates in conjunction with the college?

Research Question 2: What are clinical educators' perceptions of their preparedness in working with teacher candidates in a clinical experience?

Research Question 3: What are clinical educators' perceptions of the level of support received while mentoring teacher candidates throughout a clinical experience?

\section{Context}

As part of the continuous improvement process, a secondary content methods course was revised in Fall, 2017. Prior, the course was taught on campus in a traditional manner. In addition, students had a 25 -hour fieldwork requirement in conjunction with the course. As revised, the course is now taught at a local high 
school, and all teacher candidates do the 25-hour fieldwork requirement in the same school during the scheduled course. The course is co-taught by a faculty member, the building principal, and the clinical educators assigned to the teacher candidates. In a three-hour block, teacher candidates attend class, apply their learning in their clinical educators' classrooms, and return to the group to debrief. As the teacher candidates practice applying theory to practice in their clinical educators' classrooms, the faculty member and building principal observe them periodically and provide targeted feedback. Teacher candidates also receive ongoing feedback from their assigned clinical educator. The course was co-planned by the faculty member and building principal, including all topics addressed and required assignments. The building principal primarily used school district initiatives to guide the planning process.

Given the revisions to the course and the increased reliance on clinical educators to co-construct meaningful experiences for teacher candidates, this setting became the context for the study. As the clinical educators immersed themselves in the methods course, great opportunity emerged to study their perceptions of this newly appointed role. While none of the clinical educators were new to having a teacher candidate do fieldwork in their classrooms, they were all new to this revised model for clinical practice, thus new to the role.

\section{Research Design}

In order to ascertain the perceptions of the clinical educators involved in the revised secondary content methods course regarding their role in preparing teacher candidates through clinical experiences, a quantitative, descriptive research design was employed. A 10-question survey was developed that served to collect feedback directly from the clinical educators regarding the clinical experience (see Appendix A). The survey was created to collect data that would be used for program improvement. Therefore, three questions were written to address course-specific items such as course topics, course assignments, and the perceived value of moving the course from campus to the high school. Data collected from these questions would be used to adjust course expectations and assignments in subsequent offerings.

The remaining survey questions were developed around the three research questions. Four survey items were created to ascertain clinical educators' perceptions of the scope of their role, including their overarching responsibilities, connecting with the goals of the college, serving as a conduit to the college, and understanding the shared responsibility in preparing teacher candidates. Two survey items were composed to address clinical educators' perceptions of their preparedness to work with a teacher candidate in a clinical experience, addressing not only being well prepared for the role, but feeling confident in their work with a teacher candidate. Finally, one survey item was written to determine clinical educators' perceptions of the level of support received while engaging in the role of a clinical educator. Since there is a limited amount of literature regarding clinical educators' roles and specific responsibilities in working with teacher candidates throughout a clinical experience, these survey items were created to start a dialogue. The findings could help these specific clinical educators better define their role and help both the college and the school district establish clear expectations for all involved in developing teacher candidates through clinical experiences.

Survey items were written as statements of beliefs, and were framed using Likert-type scale responses. The survey was created in an online format, and participants were emailed the link. In the survey directions, it was clear that participation was voluntary and all information shared was confidential. Participants were informed that taking the survey would provide feedback regarding their 
experience, thus helping the partnership improve the secondary methods course experience for clinical educators in subsequent semesters.

\section{Population and Sampling}

In Fall 2017, nine undergraduate students were enrolled in the secondary methods course. Therefore, nine clinical educators were identified by the building principal. Of those nine, two were English teachers, two were Spanish teachers, one was a social studies teacher, and four were math teachers. In establishing criteria for choosing clinical educators, the building principal looked at observations collected within the teacher evaluation process, willingness to be a reflective practitioner, and impact on student learning. Convenience sampling was used with the clinical educators involved in the methods course. All nine clinical educators were invited to participate in the study.

\section{Data Collection and Analysis}

Clinical educators were sent the link for the online survey after completing their participation in the secondary content methods course during the Fall 2017 semester. The survey was sent out via Survey Monkey at the end of the semester. Data was collected in a confidential manner. All responses were compiled in order to analyze as a group, rather than by individual.

Survey data was analyzed holistically, from all participants, and was analyzed for themes. Survey items were sorted by research question, and then data was analyzed by those groupings in order to best find meaningful themes. Data was taken from Survey Monkey and put into an Excel spreadsheet, from which a frequency table was created. The frequency distributions were coded and analyzed for each survey question and then each grouping of survey questions. The data was summarized using descriptive statistics; the mode for each survey question was determined, which led to an analysis for patterns and themes.

\section{Findings}

Survey questions were primarily created to address the three research questions. Therefore, data could be sorted into one of three areas. Survey questions that were more specific to course evaluation, such as relevance of course assignments, are not included in the data below as they were used for continuous program improvement.

\section{Research Question 1: What are clinical educators' perceptions of the scope of their role to prepare teacher candidates in conjunction with the college?}

Four of the survey questions focused on how the clinical educators felt about their overarching role. The researcher sought to identify whether or not the participants fully understood what a clinical educator is responsible for, and how they are connected with the college. Table 1 contains participants' responses regarding perceptions of their role in preparing teacher candidates. 
Table 1

Perceptions around the role of the clinical educator

\begin{tabular}{llllll}
\hline Indicators & $\begin{array}{l}\text { Strongly } \\
\text { Agree }\end{array}$ & Agree & Neutral & Disagree & $\begin{array}{l}\text { Strongly } \\
\text { Disagree }\end{array}$ \\
\hline $\begin{array}{l}\text { Understand roles and } \\
\text { responsibilities of clinical educator }\end{array}$ & $29 \%$ & $29 \%$ & $42 \%$ & $0 \%$ & $0 \%$ \\
$\begin{array}{l}\text { Understand the responsibility to } \\
\text { prepare teacher candidates is shared }\end{array}$ & $29 \%$ & $57 \%$ & $14 \%$ & $0 \%$ & $0 \%$ \\
$\begin{array}{l}\text { Understand the college's goals for } \\
\text { teacher candidates }\end{array}$ & $14 \%$ & $72 \%$ & $14 \%$ & $0 \%$ & $0 \%$ \\
$\begin{array}{l}\text { Serve as a conduit between the } \\
\text { college and the classroom }\end{array}$ & $29 \%$ & $57 \%$ & $14 \%$ & $0 \%$ & $0 \%$ \\
\hline
\end{tabular}

Research Question 2: What are clinical educators' perceptions of their preparedness in working with teacher candidates in a clinical experience?

Two of the survey questions focused on perceptions of preparedness. While participants may have understood the role of a clinical educator, feeling both prepared and confident to engage in the role is a separate issue. Table 2 contains participants' responses around perceptions of preparedness in working with teacher candidates.

Table 2

Perceptions of preparedness

\begin{tabular}{|c|c|c|c|c|c|}
\hline Indicators & $\begin{array}{l}\text { Strongly } \\
\text { Agree }\end{array}$ & Agree & Neutral & Disagree & $\begin{array}{l}\text { Strongly } \\
\text { Disagree }\end{array}$ \\
\hline $\begin{array}{l}\text { Felt well prepared in role as clinical } \\
\text { educator }\end{array}$ & $0 \%$ & $57 \%$ & $43 \%$ & $0 \%$ & $0 \%$ \\
\hline $\begin{array}{l}\text { Felt confident in collaborating with } \\
\text { teacher candidate over course } \\
\text { assignments }\end{array}$ & $29 \%$ & $57 \%$ & $0 \%$ & $14 \%$ & $0 \%$ \\
\hline
\end{tabular}

Research Question 3: What are clinical educators' perceptions of the level of support received while mentoring teacher candidates throughout a clinical experience?

One of the survey questions focused on participants' perceptions of support received while serving in the role of the clinical educator. In order to maximize the experience for both teacher candidates and clinical educators, ample support is important. Table 3 contains participants' responses around perceptions of support received while working with teacher candidates. 
Table 3

Perceptions of support for clinical educators

\begin{tabular}{|c|c|c|c|c|c|}
\hline Indicators & $\begin{array}{l}\text { Strongly } \\
\text { Agree }\end{array}$ & Agree & Neutral & Disagree & $\begin{array}{l}\text { Strongly } \\
\text { Disagree }\end{array}$ \\
\hline $\begin{array}{l}\text { Felt well supported throughout } \\
\text { clinical educator experience }\end{array}$ & $43 \%$ & $29 \%$ & $14 \%$ & $14 \%$ & $0 \%$ \\
\hline
\end{tabular}

\section{Discussion}

The data suggests that participants in this study understand the overarching goal of clinical practice. They know the college's goals and feel that they can connect the college to the P-12 classroom. While the majority of participants indicated they understand that they share in the responsibility of preparing teacher candidates, nearly half remained neutral in their response to understanding the roles and responsibilities of the clinical educator. It is likely that participants understand the framework for clinical practice, but are unclear as to the specific roles and responsibilities required when serving as a clinical educator. This lack of a clear definition is consistent with the gap in the research around this topic.

The majority of participants indicated they felt prepared to work with their teacher candidate. More than half of the participants felt confident in collaborating with their teacher candidate over course assignments. However, only just over half felt well prepared for the role of clinical educator. The remaining participants remained neutral in responding to their level of preparedness. Considering teachers collaborate on a regular basis, it isn't a surprise that $86 \%$ of participants felt comfortable in that role with their teacher candidate. The shift in perceptions of preparedness seem to revolve around the overarching role of the clinical educator.

Given that the change to the methods course was new, determining how to support the clinical educators had not been fully determined. The building principal had more frequent interactions with the participants than did the faculty member, but those interactions were not necessarily formal or specific to their roles. While the majority of participants felt supported throughout the experience, just over a quarter disagreed or remained neutral regarding feeling supported. The data suggests that the type of support participants expected to receive while in the role of a clinical educator was inconsistent. The discrepancy in ways to support the clinical educator is consistent with gaps in the literature; either the clinical educators had various perceptions about what that support might look like, or clear parameters around providing clinical educators with support was lacking.

A clear trend can be found in the data. Participants did not fully understand their specific roles and responsibilities as a clinical educator when working with a teacher candidate. Nor did they feel fully prepared to engage in the role or feel completely supported in the role. Participants felt comfortable engaging in tasks with which they are familiar, such as collaborating or teaching. Their confidence in connecting the college to the P-12 classroom and participating in the secondary methods course may have come from engaging in such tasks themselves as teacher candidates in years past. Participants have engaged in these types of collaborative tasks or responsibilities either as a teacher or as a teacher candidate once themselves, so they are not completely foreign experiences. There is clear value and meaning for participants in such tasks that impact their daily work as educators, which may be why participants were more positive in their reporting. But it appears that the positive perceptions stop there. Participants did not feel completely comfortable in the role of clinical educator. Those shifts in perception around 
preparedness and support further exemplify why the gap in the research regarding the role of the clinical educator is significant and why attention must be shifted to address it. While small in scope, it would be worth replicating this study with larger populations to determine if these trends are wide-spread, further supporting just how significant the gap in the research really is.

\section{Limitations}

The sample size was a potential limitation of this study. In sampling a small population, it is possible that participants' perceptions are not reflective of larger populations. In addition, being a part of a small sample size may have impacted how participants responded to survey questions. Replications of this study with larger sample sizes would alleviate this limitation.

The limited amount of prior research was an impetus for this study, but was also a limitation of this study. The literature review was relatively small due to the limited amount of research currently available on this topic. This could have impacted the development of the survey or overall direction of the study. As more research is conducted around the role of the clinical educator, the growing body of literature available on this topic will address this limitation.

Finally, the instrument used was a limitation of the study. Given that the tool was developed by the researcher and another valid and reliable tool was not readily available, the tool may have limited the data collected. Subsequent research with other populations and other instruments would allow for a growing understanding of clinical educators' perceptions, thus decreasing this limitation. In addition, validation or reliability studies could be conducted on the tool used in this study to potentially strengthen the findings.

\section{Implications for Teacher Education Research and Practice}

There is a clear need for qualified clinical educators to ensure the learning of both teacher candidates and P-12 students. However, the roles and responsibilities of clinical educators are ill-defined. Clinical educators share in the responsibility of developing teacher candidates, but are not afforded the opportunity to truly develop themselves as a clinical educator. "Becoming and being a clinical educator is a developmental process" during which time much reflection on one's practice must take place (Higgs \& McAllister, 2007, p. 51). Preparation and support is essential, yet widely lacking (Grossman, 2010).

According to AACTE (2018), "clearly defined roles and responsibilities of both school and university partners set the stage upon which to build future success" (p. 26). Given the shared responsibility that higher education and P-12 faculty have in preparing teacher candidates, clearly defining roles and responsibilities around clinical experiences is imperative. The findings of this study suggest that clinical educators may not fully understand all of the nuances of their role, and their perceptions of preparedness and support throughout the clinical experience process is not solid. Both the gaps in the literature around the role of clinical educators and the findings of this study illustrate the need for future research.

This study leads to three major implications for future research and practice. First, the role of the clinical educator must be clearly defined. With a clear definition must also come a "common lexicon for clinical educator preparation" (AACTE, 2018, p. 39). According to AACTE (2018), clinical educators "assume coaching and partnership responsibilities in addition to their oversight of PK-12 student learning" (p. 36). But what exactly do those partnership responsibilities entail? For each teacher preparation program, partnerships with P-12 districts must be made, and those partnerships must collaboratively agree upon the roles and specific responsibilities of the clinical educators who work with 
teacher candidates. Whereas clinical educators are held just as accountable as higher education faculty for preparing teacher candidates, their specific responsibilities in the clinical practice experience must be well established. Once identified, clinical educators must be made aware of those specific roles and responsibilities.

Second, clinical educators must be well prepared to work with teacher candidates. Not only do they need to be made aware of their responsibilities, but they need proper professional development around what it means to be a clinical educator. While the clinical educator may be deemed highly effective by an administrator, that does not necessarily mean they are well prepared to mentor a teacher candidate. Training and professional development around instructional coaching, mentoring, connecting theory with practice, reflection, among other topics must occur prior to entering into a clinical educator role.

Third, ongoing support must be provided to all clinical educators. This support must come from the partnership established between the teacher preparation program and the P-12 school district. Support might mean ongoing professional development, periodic meetings to anchor in on current trends and topics, opportunities to engage in conversation with higher education faculty in order to inform course revisions, and other topics as related to clinical practice. Specifics around how to support clinical educators must be clearly determined before clinical experiences take place, and methods for support must be clearly communicated to clinical educators so they are well aware of what kinds of support will be available throughout the process. Clinical educators must feel supported as they work with teacher candidates in order to maximize the clinical experience for all involved.

As teacher preparation programs continue to evolve in order to remain current and compliant with revised accreditation standards, clinical experiences must be at the forefront of those changes. The focus cannot be on the structure or framework of clinical experiences alone. Rather, much more attention must be paid to the clinical educators involved in the process. According to CAEP (2015)

Until the research base for clinical practices and partnerships is more definitive, 'wisdom of practice' dictates that the profession move more forcefully into deepening partnerships; into clarifying and, where necessary, improving the quality of clinical educators who prepare the field's new practitioners and into delivering field and clinical experiences that contribute to the development of effective educators (para. 7).

Ample training and professional development must be provided so clinical educators know exactly what their role entails. Ongoing support must be put into place so clinical educators can continue to grow as mentors and coaches for teacher candidates. Opportunities for clinical educators and teacher preparation faculty to collaborate must be provided frequently. Ultimately, through strong partnerships between teacher preparation programs and P-12 districts, a cadre of high-quality clinical educators can emerge. In order to continue to raise the profession and train teachers to have a strong impact on student development, more work must be done to prepare the clinical educators involved in the process.

\section{Declaration of Conflicting Interests}

The author declared no potential conflicts of interest with respect to the research, authorship, and/or publication of this article.

\section{Funding}

The author received no financial support for this research. 


\section{References}

American Association of Colleges for Teacher Education. (2018). A pivot toward clinical practice, its lexicon, and the renewal of educator preparation: A report of the AACTE clinical practice commission. Retrieved from https://secure.aacte.org/apps/rl/res get.php?fid=3750\&ref $=\mathrm{rl}$.

Boyd, D., Grossman, P., Lankford, H., Loeb, S., \& Wyckoff, J. (2009). Teacher preparation and student achievement. Educational Evaluation and Policy Analysis, 31(4), 416-440. https://doi.org/10.3102/0162373709353129

CAEP Commission on Standards and Performance Reporting. (2013, June 11). CAEPaccreditation standards and evidence: Aspirations for educator preparation. Retrieved from http://www.ncate.org/ /media/Files/caep/standards/commrpt.pdf?la=en.

Council for the Accreditation of Educator Preparation. (2015). Standard 2: Clinical partnerships and practice: Rationale. Retrieved from http://caepnet.org/standards/standard-2/rationale.

Council for the Accreditation of Educator Preparation. (2016, March). CAEP accreditation handbook (version 3). Retrieved from http://caepnet.org/ /media/CAEP\%20Accreditation\%20Handbook March\%202016.pdf?la =en.

Council for the Accreditation of Educator Preparation. (2018). CAEP handbook: Initial-level programs 2018. Retrieved from http://www.ncate.org/ /media/Files/caep/accreditationresources/2018-initial-handbook.pdf?la=en.

Darling-Hammond, L., \& Baratz-Snowden, J. (2007, Winter). A good teacher in every classroom: Preparing the highly qualified teachers our children deserve. Educational Horizons, 85(2), 111132.

Grossman, P. (2010). Learning to practice: The design of clinical experience in teacher preparation. Retrieved from https://www.nea.org/assets/docs/Clinical Experience - Pam Grossman.pdf.

Grossman, P., Hammerness, K., \& McDonald, M. (2009). Redefining teaching, re-imagining teacher education. Teachers and Teaching, 15(2), 273-289. https://doi.org/10.1080/13540600902875340

Higgs, J., \& McAllister, L. (2007). Educating clinical educators: Using a model of the experience of being a clinical educator. Medical Teacher, 29(2-3), 51-57. https://doi.org/10.1080/01421590601046088

Kumar, K. \& Greenhill, J. (2016). Factors shaping how clinical educators use their educational knowledge and skills in the clinical workplace: A qualitative study. BMCMedical Education, 16(68). https://doi.org/10.1186/s12909-016-0590-8

McIntyre, D. J., (2017). The power of clinical preparation in teacher education: Themes and recommendations. In R. Flessner \& D. R. Lecklider (Ed.), The power of clinical preparation in teacher education: Embedding teacher preparation within P-12 school contexts (pp. 197-209). Lanham, MD: Rowman \& Littlefield.

Morrison, L., McBride, L. J., \& McAllister, L. (2016, December). Does an online clinical educator preparation and support program change practice? International Journal of Practice-based Learning in Health and Social Care, 4(2), 63-72. https://doi.org/10.18552/ijpblhsc.v4i2.355 
National Council for Accreditation of Teacher Education. (2010, November). Transforming teacher education through clinical practice: A national strategy to prepare effective teachers. (Report of the blue ribbon panel on clinical preparation and partnerships for improved student learning). Retrieved from http://www.highered.nysed.gov/pdf/NCATECR.pdf.

Zeichner, K. (2010). Rethinking the connections between campus courses and field experiences in college- and university-based teacher education. Journal of Teacher Education, 61(1/2), 89-99. https://doi.org/10.1177/0022487109347671 